\title{
LA COMMEMORATIO ANNUNTIATIONIS Y LA FIGURA DE SAN ILDEFONSO DE TOLEDO EN LAS VITAE SANCTORUM de Rodrigo de Cerrato. Su relación con la LITERATURA HISPÁNICA DEL SIGLO XIII ${ }^{1 *}$
}

\author{
Olga Soledad BoHDZIEWICZ ${ }^{2}$ \\ UBA - IIBICRIT (CONICET)
}

Recibido: 7 de junio de 2020

Aceptado: 21 de febrero de 2021

\begin{abstract}
Resumen
Partiendo de la compilación hagiográfica de Rodrigo de Cerrato, este trabajo propone analizar la Commemoratio Annuntiationis y la figura del santo al que se atribuye la instauración de esta celebración mariana, Ildefonso de Toledo. En conexión con las Vitae sanctorum consideraremos también otras compilaciones, tanto en lengua latina y romance, con el objeto de determinar las fuentes, su combinación e inserción en el texto y el diverso tratamiento que éstas reciben en cada caso. Ello contribuirá a verificar la continuidad de esta festividad mariana de tradición visigótica en el siglo XIII y a poner de relieve las vacilaciones que se produjeron en cuanto a su objeto.
\end{abstract}

\section{Palabras-clave}

Commemoratio Annuntiationis, Virgen María, Ildefonso de Toledo, compilaciones latinas, Rodrigo de Cerrato, Juan Gil de Zamora.

\begin{abstract}
By considering in the first place Rodrigo of Cerrato's hagiographic compilation, this paper aims to analyze the Commemoratio Anuntiationis and the representation of Ildephonsus of Toledo, the saint to whom the creation of this Marian celebration is ascribed. In connection with the Vitae sanctorum, we will also take into account other compilations, both in Latin and Romance languages, in order to find their sources, their combination and inclusion into the text, as well as the different ways they are handled in each case. This will contribute to verify the continuity of this visgothic Marian feast up to $13^{\text {th }}$ century as well as to show the hesitations regarding its aim.
\end{abstract}

\footnotetext{
1 * Expresamos nuestro agradecimiento al Madrid Institute for Advanced Study (MIAS), que a través de una estancia de investigación en la Casa de Velázquez y la Universidad Autónoma de Madrid nos ha permitido acceder a recursos indispensables para llevar a cabo este trabajo.

2 Departamento de Letras Clásicas, Instituto de Filología Clásica, Universidad de Buenos Aires- Instituto de Investigaciones Bibliográficas y Crítica Textual, Consejo Nacional de Investigaciones Científicas y Técnicas (IIBICRIT-CONICET). Correo electrónico: soledad.bohdziewicz@conicet.gov.ar. ORCID: https:// orcid.org/0000-0002-7234-4377.
} 


\title{
Keywords
}

Commemoratio Annuntiationis, Virgin Mary, Ildephonsus of Toledo, latin compilations, Rodrigo of Cerrato, Juan Gil of Zamora.

\begin{abstract}
Von Rodrigo de Cerratos hagiographischem Sammelwerk ausgehend, wird die Analyse der Commemoratio Annuntiationis und der Heiligenfigur, der die Einsetzung dieser marianischen Feier zu verdanken ist, Ildefonso de Toledo, in dieser Arbeit beabsichtigt. In Verknüpfung mit den Vitae sanctorum ziehen wir auch andere Sammelwerke in Betracht, sowohl aus der lateinischen als auch aus der spanischen Sprache, und zwar mit dem Vorhaben, die Quellen, ihre Verbindung und ihren Einsatz in den Text und deren unterschiedliche Behandlung in jedem Fall zu bestimmen. Das trägt sowohl zu der Bestätigung der Fortdauer dieser marianischen Feier aus westgotischer Tradition aus dem XIII. Jahrhundert als auch zu der Hervorhebung des Schwankens, das sich seines Zweckes bezüglich ergab, bei.
\end{abstract}

\section{Schlüsselwörter}

Commemoratio Annuntiationis, Jungfrau Maria, Ildefonso de Toledo, lateinische Sammelwerke, Rodrigo de Cerrato, Juan Gil de Zamora.

\section{La compilación del cerratense}

Como la de sus contemporáneos, Juan Gil de Zamora y Bernardo de Brihuega, la obra del dominico Rodrigo de Cerrato ${ }^{3}$ constituye un representativo ejemplo de una de las principales formas de producción literaria en lengua latina en Castilla durante el siglo XIII: la compilación. Vale decir que este tipo de obra es el resultado de un trabajo de selección, recorte y, muchas veces, reordenamiento de fuentes diversas, fuentes que, según explica el propio fray Rodrigo en un breve prólogo, se hallaban dispersas en distintos volúmenes y que él recogió y acondicionó con el objetivo fundamental de facilitar a sus hermanos de la Orden la tarea de la predicación:

"Vitas Sanctorum nimia prolixitate descriptas ac uariis uoluminibus dispersas, quorum festa Ecclesia colit uel quorum historias fides fidelium recipit, breuiter et succinte eligens utilia in uno uolumine perstringere curaui, explosis coloribus purpuratis, quatinus prolixitas, mater tedii, lectorem non retrahat, breuitas alliciat, utilitas inducat, color rectoricus non abducat, predicatoribus uero ad predicandum de sanctis non desit materia et ad excitandam deuocionem

\footnotetext{
La obra de Rodrigo de Cerrato ha sido editada a partir del manuscrito de Segovia por Francisco VILLAmIL FERNÁNDEZ, (ed.), Rodrigo de Cerrato, Vitas sanctorum. Estudio y edición (tesis doctoral), Universidade de Santiago de Compostela, Santiago de Compostela, 1991. Una nueva edición crítica que considera todos los testimonios conocidos de las Vitae sanctorum ha sido preparada por Massimiliano Bassetti y se espera su pronta publicación a través de SISMEL.
} 


\section{fidelium deuota inueniantur exempla, clericos quoque inopes ad habendum uitas sanctorum inopia non excuset". ${ }^{4}$}

Las Vitae sanctorum de Rodrigo de Cerrato se han transmitido a través de tres códices: 1) Segovia, Biblioteca Capitular, B-275, siglo XIII (S); 2) Madrid, Biblioteca de la Universidad Complutense, 146, siglo XIV (M) y 3) Londres, British Library, Add. 30057, siglo XIV $(\mathrm{L})^{5}$. Hay noticias de otro manuscrito que se conservaba en la Biblioteca Alcobacense bajo el número 123, hoy perdido ${ }^{6}$. De la comparación de los contenidos de los tres manuscritos, puede constatarse la existencia de al menos dos estadios de redacción. Para los manuscritos de Londres y de Madrid puede fijarse 1260 como fecha ante quem, esto es, antes de la difusión de la Legenda aurea del dominico Jacobo de Varazze, de la que se incluyen 16 vidas en el manuscrito de Segovia. Sobre este último puede decirse, con mayor precisión, que el texto que transmite fue concluido en 1276 , fecha en la que, según el propio fray Rodrigo, confeccionó el apartado con cómputos de la vida de María y de Jesús con el que concluye su compilación (Segovia, Biblioteca Capitular, B-275, ff. 225rb-226va).

En cuanto a la organización de sus contenidos, la obra del cerratense presenta las vidas de los santos y demás festividades de acuerdo con el año litúrgico, comenzando con la Natividad de la Virgen, a diferencia de lo que ocurre en el santoral de Bernardo de Brihuega, obra compuesta a pedido de Alfonso $\mathrm{X}$, en la que las vidas van clasificadas por tipos (mártires, vírgenes, confesores, etc.), o las Legende sanctorum de Juan Gil de Zamora donde, como en varias de sus obras, el franciscano adopta una disposición alfabética.

\footnotetext{
4 Villamil Fernández, Francisco (ed.), Vitas sanctorum, p. 100.

En referencia a la tradición manuscrita de la obra de Rodrigo de Cerrato, $c f$. Javier PÉREz-EMBID WAMBA, Hagiología y sociedad en la España medieval. Castilla y León (siglos XI-XIII), Universidad de Huelva, Huelva, 2002, p. 216; Antoine Dondaine, "Les editions du 'Vitas Sanctorum' de Róderic de Cerrato", Studia Anselmiana, 63 (1974), pp. 225-253; Massimiliano BASSETTI, "Per un'edizione delle «Vitae sanctorum» di Rodrigo del Cerrato", Hagiographica, 9 (2002), p. 74 n. 4. Los manuscritos London, Bithish Library, Add. 23935; Paris, Bibliothèque Nationale, Lat. 2333, ff. 39vb-40va y Paris, Bibliothèque Nationale, Lat. 2333A, ff. 1ra-1vb, que son incluidos por Dondaine como testimonios de la obra del cerratense, no se hallan relacionados con su obra. El manuscrito londinense contiene obras vinculadas a la Orden de los Predicadores cuyo contenido ya ha sido descripto con detalle en Gretchen R. Galbraith, The Constitution of the Dominican Order, Manchester University Press, Manchester, 1925, pp. 193-202. Los dos manuscritos franceses, por otra parte, a pesar de la descripción de la Bibliothèque Nationale de France, transmiten un milagro identificado con el número 590 en el índice de Poncelet, presente en numerosas colecciones de milagros marianos. $C$ f. Albert Poncelet, "Index Miraculorum B.V. Mariae quae saeculis VI-XV latine conscripta sunt", Analecta Bollandiana, XXI (1902), pp. 241-360. Inc.: "Fuit in Toletana urbe quidam archiepiscopus, qui vocabatur".

6 Cf. Fortunato de SAn Bonaventura, Commentariorum de Alcobacensi manuscriptorum bibliotheca libri tres, Typographia Academico-Regia, Coimbra, 1827, pp. 27 y 510. Thomas L. Amos, The Fundo Alcobaça of the Biblioteca Nacional, vol. 1: Manuscripts 1-150, Lisbon, Collegeville (Minnesota), 1988, p. XXXVI.
} 


\section{La Commemoratio Annuntiationis en la Castilla del siglo XIII}

Las Vitae sanctorum incluyen cinco apartados relativos a festividades de la Virgen ${ }^{7}$, de las cuales la Commemoratio Annuntiationis sólo aparece en el manuscrito de Segovia. Conocida bajo múltiples denominaciones ${ }^{8}$, esta celebración fue fijada en el año 656 por el X Concilio de Toledo, en el que se presume que san Ildefonso habría participado, aunque su nombre no figura en la lista de los asistentes ${ }^{9}$. En cambio, sí hay constancia de su presencia en los dos Concilios anteriores, celebrados en 653 y 655, en tiempos de su abadiato en Agali. Que su nombre no se halle en 656 puede deberse, como explica Martín Iglesias, al hecho de que las actas de este concilio, a diferencia de otras, se hallan suscriptas únicamente por los obispos o sus representantes ${ }^{10}$.

El primer canon, de los seis aprobados en el X Concilio, tiene por objeto, como decíamos, el establecimiento de la fecha común para la celebración de la Virgen. La falta

7 Su localización en los manuscritos es la siguiente: De Nativitate beate Virginis Mariae (M, ff. 1ra-2ra, L 6ra-7ra, [1ra-2ra], S, 1ra-4ra), De festo beate Virginis Marie (Commemoratio Annunciationis) (S, 54ra54vb), De festo Purificationis beate Marie (M, 105ra-106ra, L, 78rb-78va [74rb-74vb], S, 227ra -231ra), De Annunciatione (M, 122va-124va, L, 88vb-90ra [84vb-86ra], S, 108rb-109vb), De Assumptione beate Virginis Marie (M, 206va-222ra, L, 138vb-149ra [134vb-144ra], S, 108rb-109vb). Entre corchetes cuadrados se indica la foliación antigua. Hay una anotación marginal en S, f. 96v, al costado de la vida de santa Brígida, en letra del s. XIV: "Hic deficit de Purificatione Virginis Marie, sed requirere in fine huius libri ultimo quaterno, folio CCXXVII". Es una versión ampliada con respecto a la de los manuscritos M y L.

8 En los calendarios examinados por Férotin la fiesta del 18 de diciembre aparece consignada como Sancte Marie Virginis (pp. 490-491), salvo por el calendario de Córdoba (“códice G") del año 961, que le da el nombre de Apparitio Marie (p. 491), por la que se debe entender, según este erudito francés, Apparitio Gabrielis angeli Virgini Marie. En el calendario del "códice B", datado en 1052, también se consigna el 20 de marzo la Conceptio Sancte Marie Virginis, que también aparece en el calendario fragmentario mozárabe de fines del siglo XI, pero en el día 22 (pp. 458-496). Marius Férotin, Le Liber Ordinum en usage dan l'église wisigothique et mozarabe d'Espagne du cinquième au onzième siècle, Monumenta Ecclesiae Liturgica, Firmin-Didot, Paris, vol. 5, 1904. Frías da cuenta de las siguientes formas para referirse a la celebración: Commemoratio Annuntiationis (pp. 44, 109), Conceptio Sanctae Mariae (pp. 33, 38-39), Expectatio (pp. 101, 129, 149, 150). Lesmes Frías, "Antigüedad de la fiesta de la Inmaculada en España”, Miscelánea Comillas, 23 (1955), pp. 27-154. En la Estoria de España se refiere la celebración como "el dia de la fiesta de sancta Maria-la que fazen mediado deziembre en Espanna". Ramón MENÉnDEZ Pidal (ed.), Primera crónica general de España, Gredos, Madrid, 1977, t. 1, p. 282. En el epígrafe de la cantiga 413 de Alfonso X, por su parte, se consigna de esta manera: "esta terceira é da virgĩidade de santa Maria, e esta festa é no mes de dezenbro, e feze-a sant'Alifonsso". Walter Mettmann (ed.), Alfonso X, el Sabio, Cantigas de Santa María, Castalia, Madrid, t. 3, 1989, pp. 332-333. La denominación Expectatio Partus aparecería reflejada en los sínodos a partir de 1330. Adeline RucQuoI, "Ildefonse de Tolède et son traité sur la Virginité de Marie", La Virginité de Marie. Communications présentées à la 53e session de la Société française d'études mariales, Issoudun, septembre 1997, Médiaspaul, París, 1998, p. 122. Las advocaciones de Nuestra Señora de la O y la Virgen de la Esperanza se relacionan con esta celebración. 9 José Vives (ed.), Concilios Visigóticos e Hispano-Romanos, Consejo Superior de Investigaciones Científicas Instituto Enrique Flórez, Barcelona, Madrid, vol. 1, 1963, pp. 308-310. David Paniagua, "Concilios hispánicos de época visigótica y mozárabe”, La Hispania visigótica y mozárabe. Dos épocas en su literatura, Carmen Codoñer (coord.), Universidad de Salamanca, Universidad de Extremadura, Salamanca, 2010, p. 311.

10 José Carlos Martín Iglesias, "Ildefonso de Toledo", Diccionario biográfico español, Real Academia de la Historia, Madrid, vol. 27, 2012, p. 187. 
de consenso sobre el momento exacto de llevarla a cabo se debía a que con frecuencia coincidía con la Cuaresma o la Pascua, períodos en los que no estaba permitido celebrar otras solemnidades ${ }^{11}$, por lo que constituía una festividad móvil. A causa de la preocupación de que la falta de uniformidad tuviese la indeseable consecuencia de un cisma, se establece entonces el 18 de diciembre, una semana antes de la Natividad de Jesús, como la fecha para la celebración mariana de la Anunciación.

La implantación del rito romano, introducido tempranamente en Cataluña, se produjo, no sin resistencias, durante el último cuarto del siglo XI en el reino castellano-leonés. En pleno siglo XIII esta celebración constituiría un ejemplo de la continuidad de ciertas tradiciones de la antigua liturgia hispánica junto al rito romano. Un pasaje de la Estoria de España da cuenta justamente de la pervivencia de algunas prácticas a pesar de la generalización de este último:

"Et desde estonces ell officio gallicano, fascas ell officio francés, tanbien en el Salterio como en las otras leendas fue allí [Toledo] recebido estonces en las Espannas et guardado, lo que nunqua antes fuera. Et maguer que en algunos monesterios guardaron yaquanto tiempo después el de Espanna, et el traslado del salterio aun oy se reza en algunas de las eglesias cathedrales et en los monesterios mayores: pero al común, el de Francia anda por toda la tierra, et aquel usan al común en la escriptura de las letras et en ell oficio". ${ }^{12}$

Tanto la obra de Gonzalo de Berceo como Alfonso X, principales testimonios literarios de poesía mariana en lengua vernácula, dan cuenta de la continuidad de la celebración de la fiesta del 18 de diciembre dedicada a María y ésta viene indefectiblemente ligada al nombre de san Ildefonso. Se encuentra asimismo en la traducción del Liber iudiciorum, donde en la versión de Ervigio, correspondiente al año 681, se ordenaba que los judíos debían abstenerse de realizar labores durante los domingos y un cierto número de celebraciones entre las que se cuenta la dedicada a la Virgen, a la que se

\footnotetext{
11 Un reciente estudio analiza el origen de esta festividad y su relación con desarrollos mariológicos contemporáneos en otros lugares de Europa. Kati Iнnat, “Orígenes y desarrollo de la fiesta litúrgica de la Virgen María en Iberia”, Anuario de Estudios Medievales, 49. 2 (2019), pp. 619-643. La autora halla una sugestiva conexión con el dogma de la perpetua virginidad de María, fijado en el concilio de Letrán en 649 y la presencia en ese mismo tiempo de Tajón en Roma, que da lugar a pensar en una posible influencia de esta última sobre la Península Ibérica. En relación con el X Concilio de Toledo véase especialmente la p. 621.

12 Citamos por la edición de Menéndez Pidal, aunque contrastamos este capítulo con la transcripción del manuscrito $\mathrm{E}_{2}$ (Escorial X-I-4, ff. 179r-180v), que en esta porción del texto corresponde a la versión amplificada de 1289, disponible en Aengus WARD (ed.), Estoria de Espanna Digital, University of Birmingham, consultado el 13-02-2020, http://estoria.bham.ac.uk/edition/. Cf. Ramón MenÉndEz PIDAL (ed.), Primera crónica general de España, Gredos, Madrid, t. 2, 1977, p. 543.
} 
refiere con el término conceptio ${ }^{13}$. Como ha señalado Frías ${ }^{14}$, la versión romanceada esclarece la ambigüedad que podía generar la expresión del texto latino traduciendo "la Anunciación cuando concebió del Santo Espíritu"15, a la vez que suma la Asunción entre las celebraciones que deben ser observadas.

En conexión con la conmemoración de la Anunciación en el mes de diciembre ha de verse además el surgimiento de una nueva manifestación artística que, según explica Sánchez Amejeiras ${ }^{16}$, tiene su origen en León y Zamora a fines del siglo XIII, desde donde irradió al resto del área castellano-leonesa, Galicia y Portugal. Se trata de las "Anunciaciones preñadas", esto es, grupos escultóricos en los que se representa a Gabriel dando la salutación angélica a una María en un avanzado estado de gravidez ${ }^{17}$. Dada la inclusión de esta celebración mariana en las Cantigas de Santa Maria, la autora nos habla de un "nuevo impulso"18 de la fiesta de cuño alfonsí, que, a pesar de la introducción de la Anunciación de marzo según el rito romano, seguiría celebrándose ${ }^{19}$.

La incertidumbre respecto de la procedencia y datación de muchos de los calendarios que se hallan en manuscritos litúrgicos, a lo que se añade su frecuente actualización a través del tiempo según la evolución de las celebraciones, obliga a tomar con mucha cautela la información que podemos extraer de ellos, en especial, cuando su consulta está mediatizada por transcripciones o ediciones con criterios no siempre explícitos. A falta de un estudio que proponga un rastreo sistemático de las celebraciones marianas en calendarios hispánicos medievales, apuntaremos algunas observaciones de carácter preliminar: en manuscritos anteriores al siglo XII prevalece la presencia de la festividad de diciembre, a la que se consigna simplemente como "sancte Marie virginis", sin mayores precisiones, lo que se condice con su carácter de única fiesta mariana en la liturgia hispana antigua, a la que luego se sumarían otras celebraciones, en primer lugar,

\footnotetext{
13 "Dies tamen ipsi, qui ab eisdem Iudeis sollicita devotione sunt observandi, hi sunt, id est, festum Virginis Sancte Marie, quo gloriosa eiusdem genitricis domini conceptio celebratur, item natalis Christi vel circumcisionis sive apparitionis sue dies, Pasca quoque sanctum vel dies sacratissimi octavarum, inventionis quoque crucis dominice festum necnon et ascensionis dominice diem vel Pentecosten seu etiam concurrentes per totum annum dies dominicos, religiosa Christi fide venerabiles dies". [XII.III.VI] Karl Zeumer (ed.), Leges visigothorum, MGH, Hahn, Hannover, Leipzig, vol. 1. 1, 1902, pp. 434-435.

14 Lesmes Fríss, “Antigüedad de la fiesta de la Inmaculada”, p. 33.

15 Fuero juzgo en latín y castellano, Real Academia Española (ed.), Madrid, 1815, p. 190, col. b.

16 María del Rocío SÁnchez Amejeiras, "Crisis, ¿qué crisis?: sobre la escultura castellana de la primera mitad del siglo XIV”, El Trecento en obres. Art de Catalunya $i$ art d'Europa al segle XIV, Rosa Alcoy (ed.), Universitat de Barcelona, Barcelona, 2009, pp. 243-272.

17 Un estudio de las variaciones iconográficas de las Anunciaciones Preñadas y una exploración sistemática de su localización puede verse en Tomás IbÁÑez Palomo, "La Anunciación del Monasterio de Caleruega (Burgos): contextualización en la Baja Edad Media peninsular”, Anales de Historia del Arte, 25 (2015), pp. 19-49.

18 Ibidem, p. 252.

19 Para la primera mitad del siglo XIII contamos, por ejemplo, con la referencia de Pedro Andrés, obispo de Astorga, quien precisa en su testamento, redactado en 1226, que su ordenación tuvo lugar el día de la festividad de la Virgen de diciembre de 1205. Enrique Flórez, España sagrada, Imp. Gabriel Ramírez, Madrid, t. 16, 1762, p. 226.
} 
la de la Asunción ${ }^{20}$. Entre los ejemplos más antiguos donde encontramos consignada la celebración de la Virgen del 18 de diciembre, se cuenta el calendario redactado en lengua árabe en el año 961 por Rabi ben Zaid (Recemundo), obispo de Granada y traducido a la latina por Gerardo de Cremona, posiblemente bajo el auspicio de Alfonso $\mathrm{X}^{21}$. Allí se refiere a la fecha como "festum apparitionis", lo que según Simonet ha de leerse como "festum expectationis", aunque según surge de la comparación que realiza con otro calendario árabe escurialense, el término 'aparición' (tdohúr) podría acaso apuntar al milagro con que la Virgen benefició a san Ildefonso el día de su festividad. A pesar de que la implantación de la liturgia francorromana diluyó la proscripción de celebraciones en período cuaresmal e implicó un solapamiento en el objeto de las festividades marianas de marzo y de diciembre, la tradición de esta última gozó de una larga continuidad y también difusión territorial dentro y fuera de la península ${ }^{22}$. En el calendario añadido al comienzo de la copia matritense de las Vitae sanctorum, que ocupa los actuales folios 4 a 6 , en lo que parece ser letra contemporánea a la de la copia del resto del manuscrito, del siglo XIV, no se registran originalmente festividades de la Virgen en el mes de diciembre, pero dos manos diferentes añadieron la santificación de la Virgen para el día 8 y la conmemoración para el 18. Según apunta Towney, en coincidencia con las conclusiones del relevamiento realizado por Frías, la presencia de esta fiesta mariana en los libros litúrgicos irá disminuyendo su frecuencia en los siglos XIV y XV frente a la celebración de la Concepción el 8 de diciembre ${ }^{23}$.

\section{Vacilaciones en torno al objeto de la celebración}

El apartado dedicado a la celebración mariana de la Conmemoración de la Anunciación, como hemos mencionado antes, se halla únicamente en el manuscrito de Segovia de las Vitae sanctorum de Rodrigo de Cerrato después de la vida de santa Lucía (13 de diciembre). Según señala allí fray Rodrigo, hay cuatro fiestas de la Virgen que se celebran universalmente: la Natividad, la Anunciación, la Purificación y la Asunción. El festejo al que aquí se refiere -dice- difundido en ciertas partes de España, a pesar

20 Cf. José Janini, Ramón GonzÁlvez, Catálogo de los manuscritos litúrgicos de la Catedral de Toledo, Diputación Provincial, Toledo, 1977; José JaninI, José Serrano, Manuscritos litúrgicos de la Biblioteca Nacional, Dirección General de Archivos y Bibliotecas, Madrid, 1969; José Vives, Ángel FÁBrega, "Calendarios hispánicos anteriores al s. XII", Hispania Sacra, 2.3 (1949), pp. 119-146; "Calendarios hispánicos anteriores al s. XIII”, Hispania Sacra, 2. 4 (1949), pp. 339-380; “ Calendarios hispánicos anteriores al s. XIII", Hispania Sacra, 3. 5 (1950), pp. 145-161.

${ }_{21}$ Francisco Javier Simonet, "Un santoral hispano-mozárabe del siglo X”, Ciudad de Dios, V (1871), pp. $105-116$ y $192-222$.

22 Cf. Gratiniano Nieto Gallo, "Una representación de la Inmaculada en el siglo XV", Boletín del Seminario de Estudios de Arte y Arqueología, 11 (1944-1945), p. 8.

${ }_{23}$ Lesley Twomey, The Serpent and the Rose: The Immaculate Conception and Hispanic Poetry in the Late Medieval Period, Brill, Leiden, Boston, 2008, p. 14-15. Lesmes FríAs, "Antigüedad de la fiesta de la Inmaculada". Otros ejemplos de la pervivencia de la celebración en el siglo XIV pueden verse en María José Martínez Martínez, "Las anunciaciones góticas burgalesas y los ritos hispánico y romano", Codex aquilarensis: Cuadernos de investigación del Monasterio de Santa María la Real, 28 (2012), pp. 209-210. 
de la opinión de algunos, no tiene su origen en la concepción de la Virgen, ya que fue concebida en pecado original ${ }^{24} \mathrm{y}$, por esta causa, no hay motivo alguno de celebración de este hecho que, por otra parte, se produjo el vI[I ${ }^{\circ}$ idus decembris ${ }^{25}$. Se trata de un punto respecto del cual los compiladores latinos del siglo XIII castellano se esforzaron en subrayar que se trata de una prerrogativa exclusivamente concedida a Cristo.

Por su parte, Juan Gil de Zamora dedicó los tratados IV y V del Liber Marie a la cuestión de la concepción y la santificación de la Virgen. Y si bien hay afirmaciones concluyentemente maculistas, es cierto también que no se mostró completamente inflexible hacia las manifestaciones de piedad inmaculista, siguiendo de este modo la postura del General de su Orden, Buenaventura ${ }^{26}$. Así pues, el franciscano se permitió incorporar, aunque dejando constancia de su naturaleza "apócrifa", los milagros inmaculistas del hijo del rey de Hungría [Fita 53, Poncelet 1016] y del abad Elsino [Fita 51, Poncelet 714]. En la obra de Rodrigo de Cerrato, en definitiva, lo mismo que en la del franciscano Juan Gil, se esgrimen argumentos contrarios al inmaculismo, que deja translucir su presencia y avance, de la que, con las reservas del caso, ya una centuria antes el monje benedictino Hermann de Tournai habría dejado constancia ${ }^{27}$.

Sabemos a través de la carta que precede a su colección de milagros de la Virgen $[B H L$ 5398], compuesta entre 1140 y 1146 y dedicada al obispo de Laón, Bartolomé de Joux, que Hermann de Tournai había copiado a pedido de éste el tratado de Ildefonso sobre la virginidad de María, que hizo preceder de una vida del santo [BHL 3920]. Yarza Urquila ha señalado la dependencia de la uita compuesta por Hermann respecto de la

\footnotetext{
24 "Sane festum quod hodie in quibusdam Hypanie partibus agitur non est festum conceptionis ipsius Virginis, ut quidam <non> recte intelligunt". Rodericus Cerratensis, Vitae sanctorum, Ms. Segovia, Biblioteca Capitular, B-275 fol. 54ra. Introducimos la enmienda ya apuntada por Frías, necesaria para la correcta comprensión de la argumentación subsiguiente en el texto del cerratense. Lesmes FríAs, "Antigüedad de la fiesta de la Inmaculada", p. 117. Francisco Villamil Fernández (ed.), Vitas sanctorum, p. 224, no la consigna en su edición, pese a que en el facsímil del manuscrito, entre quidam y recte, parece haber una marca de inserción y en letra muy pequeña se añade la forma abreviada de non. Agradecemos al evaluador sus observaciones respecto de la lectura del facsímil.

25 Ms. Segovia, Biblioteca Capitular, B-275 fol. 54rb. Se trata con toda probabilidad de un error de copia, ya que la concepción de la Virgen se presenta con uniformidad en el occidente latino el ocho de diciembre. El propio Rodrigo en la explicación de la tabula que hallamos al final del manuscrito de Segovia dice: "Concepta est beata Virgo quasi in fine istius anni, scilicet VI ${ }^{\circ}$ idus decembris, in die dominica in F littera era XXIII". (f. 225v)

26 "Sunt tamen aliqui qui ex spirituali deuotione celebrant conceptionem beateVirginis, quos nec omnino laudare nec simpliciter audeo reprehendere". Juan Gil de Zamora, Liber Marie, Tract. IV. Remitimos a Olga Soledad Bohdziewicz (ed.), Una contribución al estudio de la prosa latina en la Castilla del siglo XIII: edición crítica y estudio del Liber Mariae de Juan Gil de Zamora (tesis doctoral), Facultad de Filosofía y Letras de la Universidad de Buenos Aires, Buenos Aires, 2014, p. 202. El texto de la tesis está disponible en línea en el Repositorio Digital de la Facultad de Filosofía y Letras de la Universidad de Buenos Aires, consultado el 12-12-2020, http://repositorio.filo.uba.ar/handle/filodigital/4412. Lamentamos que la versión que allí se halla cuente con numerosas erratas. $C f$. Bonaventura, Commentaria in quattuor libros Sententiarum magristri Petri Lombardi, In distinctionem III, Pars I, De sanctificatione Beatae Virginis. Bonaventura, Opera omnia, Collegium a S. Bonaventura (ed.), Quarrachi, vol. 3, 1887, p. 63.

27 Valeriano Yarza Urquiola, "La Vita vel Gesta Sancti Ildefonsi de ps. Eladio: estudio, edición crítica y traducción”, Veleia, 23 (2006), pp. 286-287.
} 
hagiografía atribuida a Eladio, fuente a su vez de las Vitae sanctorum. Pero nos interesa resaltar aquí que Hermann asocia el nombre de Ildefonso a la institución de una festividad en honor de la Virgen, pero no en el marco de la Anunciación, sino referido a la de la propia María, dando además como fecha el 8 de diciembre: "Unde etiam festum Conceptionis sanctae Mariae, quo scilicet ipsa concepta est, celebrare constituit, et eius constitutione per totam Hispaniam sollemniter colitur sexto idus decembris ${ }^{28}$ ".

Tenemos noticia de que Hermann había estado en España, posiblemente entre 1136 y $1138^{29}$, por una epístola que dirige a Anselmo, abad de Saint-Vincent de Laon [BHL $8649]^{30}$. El motivo del viaje habría sido la búsqueda de unas reliquias que Alfonso I el Batallador, rey de Aragón, había prometido a su primo, el obispo Bartolomé, entre las cuales se suponía que se contaba la casulla de san Ildefonso y los restos del mártir san Vicente que se conservaban en Valencia. Allí, sin embargo, su misión se vio frustrada tanto por la muerte del rey como por la imposibilidad de llegar a Valencia a causa de la ocupación musulmana. Pero no resulta tan claro que su conocimiento sobre la vida y textos de san Ildefonso se deriven necesariamente de su estancia española, como sostiene Saint-Denis ${ }^{31}$.

Como el propio Hermann aclara, su copia del De uirginitate la ha realizado a partir de un códice que ha hallado en Châlons-en-Champagne ${ }^{32}$ derivado, según demuestra Yarza Urquiola, no sólo de la copia que Gómez realizó para Gotiscalco, obispo de Le Puy-en-Velay, sino también de otra familia de manuscritos que transmite una versión interpolada del Elogium de san Julián ${ }^{33}$. No hay, sin embargo en las cartas ninguna referencia explícita a la escritura de la uita de Ildefonso a partir de averiguaciones hechas en España, como sí las hay de las passiones que copió en Zaragoza. Nos resulta difícil conjeturar, por ello, acerca de esta referencia a la festividad de la concepción mariana. ¿Constituye un reflejo de las vacilaciones sobre el propósito del festejo en la propia España -antecediendo al menos en una centuria a las dudas transmitidas por el

\footnotetext{
28 Citamos a partir de José María Canal, quien reproduce la uita de Hermann de Tournai a partir del texto de Mabillon de 1733, aunque señala haber consultado el manuscrito Paris, Bibliothèque nationale, Lat. 12593, que éste utilizó para su edición. José María CANAL "San Ildefonso de Toledo. Historia y leyenda", Ephemerides mariologicae, 17 (1967), p. 459. Cf. Acta Sanctorum Ordinis sancti Benedicti, Venecia, 1733, pp. 498-500. Por ser el único que transmite la obra de Hermann íntegramente, Saint-Denis atribuye especial importancia a este manuscrito parisino, al que se suman otras seis copias más o menos completas. Alain SAINT-Denis, "Édition des sources d'histoire médiévale: Les miracles de sainte Marie de Laon d'Hériman de Tournai”, Bulletin du centre d'études médiévales d'Auxerre, 13 (2009), consultado el 18-12-2020, http://journals.openedition.org/cem/11241.

29 Cf. Gerlinde Niemayer, "Die Miracula S. Mariae Laudunensis des Abtes Hermann von Tournai. Verfasser und Entstehungszeit”, Deutsches Archiv für Erforschung des Mittelalters, 27 (1971), pp. 152-154. Alain SAInT-Denis, "Hermannus monachus. Qui était vraiment l'auteur du livre des Miracles de NotreDame de Laon ?", Comptes rendus des séances de l'Académie des Inscriptions et Belles-Lettres, 150 année, 3 (2006), p.1640.

30 Epistola Hermanni, abbatis S. Martini Tornacensis, de corpore S. Vincentii diaconi Valentiae quiescente et de coenobio ejusdem nomine ibidem consecrato, Analecta Bollandiana, 2 (1883), pp. $243-247$.

31 Alain SAint-Denis, (2006), "Hermannus monachus", p. 1640.

32 Sobre este asunto véase José María CANAL, "San Ildefonso de Toledo", p.449.

33 Valeriano Yarza Urquiola, "La Vita vel Gesta Sancti Ildefonsi”, p. 287.
} 
cerratense- o ha de verse en relación con la expansión del culto a la concepción de la Virgen en Francia, que ya en 1139 había suscitado la enconada protesta de Bernardo de Clairvaux ${ }^{34}$ ?

Volviendo a Rodrigo de Cerrato, vemos que a la aclaración sobre la concepción añade que el origen de la festividad de diciembre tampoco ha de vincularse a la santificación de la Virgen, que necesariamente hubo de tener lugar después de su animación. Tras dar una serie de consideraciones que explican las diferencias de la animación del cuerpo según el sexo, no se atreve finalmente a pronunciarse acerca del momento de la santificación de María en el vientre de su madre: "De die tamen illa et hora solus ille nouit qui eam solus santificauit ${ }^{35}$ ". Estas precisiones resultan particularmente significativas, ya que ponen en evidencia la diversidad de opiniones que corrían en ese tiempo acerca del objeto de la festividad mariana.

El fin de ésta, según señala fray Rodrigo, que parece tener bien presente el texto conciliar, es la Commemoratio Annuntiationis, justificada en el hecho de que, por su proximidad con la Pascua, la Anunciación no suele ser debidamente celebrada. A causa de ello se resolvió establecerla en tiempos de Adviento, ocho días antes del Nacimiento de Cristo, es decir, el 18 de diciembre. Esta conmemoración, añade, fue instituida por san Ildefonso, atribución que es una constante en los textos sobre el santo de los últimos siglos de la Edad Media. Para finalizar el apartado de la fiesta se incluyen dos milagros relativos a san Ildefonso presentados aquí de manera sintética, ya que se encuentran también en la parte relativa a la festividad del santo el 23 de enero ${ }^{36}$ : el primero, la intervención de santa Leocadia proclamando una alabanza del santo toledano por los méritos de su De uirginitate, obra en la que defiende la perpetua virginidad de María; el segundo, el milagro de la vestidura que la Virgen obsequia al santo.

\section{La figura de san Ildefonso de Toledo en las compilaciones latinas}

Tal como lo anticipa al tratar de la Commemoratio Annunciationis, en su correspondiente apartado [BHL 3921] ${ }^{37}$, Rodrigo de Cerrato desarrolla en extenso la vida de san Ildefonso desde su infancia hasta la aparición de la Virgen, sin que se narre el final de su vida, presente, sin embargo, en la uita anónima, composición hagiográfica que ha servido al cerratense como fuente principal. Como ha observado su editor ${ }^{38}$, esta uita

34 Cf. Marie-Bénédicte DARY, "Saint Bernard et l'Immaculée Conception : La question liturgique", Revue Mabillon, 13 (2002), pp. 219-236.

35 Francisco Villamil FernÁndez, Vitas sanctorum, p. 224.

36 Hec autem hic breuiter posui quia in festo beati Illefonsi plenius inuenitur. Cf. ibidem.

37 Se halla entre los ff. 89ra-90ra, Francisco Villamil Fernández (ed.), Vitas sanctorum, pp. 306-309.

38 José Carlos Martín Iglesias, "Una 'Vita s. Ildefonsi' inédita, fuente de Juan Gil de Zamora. Presentación y edición del texto", Estudios de latín medieval hispánico: actas del V Congreso internacional de latín medieval hispánico, Barcelona, 7-10 de septiembre de 2009, José Martínez Gázquez, Óscar de la Cruz Palma, Cándida Ferrero Hernández (eds.), Firenze, SISMEL, 2011, pp. 194-195. Una traducción de este texto realizada por el propio editor y la noticia del descubrimiento de cuatro nuevos testimonios de la obra puede verse en José Carlos MARTín IgLESIAS, "Relatos hagiográficos sobre algunos obispos de la 
no sólo fue empleada por Rodrigo de Cerrato, sino también por Juan Gil de Zamora y Bernardo de Brihuega ${ }^{39}$. Este último la utilizó para el apartado dedicado al santo dentro de la obra que compuso a pedido de Alfonso $\mathrm{X}^{40}$, que constaba de cinco libros de contenido hagiográfico conservados fragmentariamente.

En las Vitae sanctorum, para el episodio relativo a la Virgen, la uita anónima se combina además con la versión que se halla en las colecciones universales de milagros marianos [Poncelet 884]. Ello explica que sean dos las apariciones con las que la Virgen honró a san Ildefonso, de las que se deja registro tanto en la parte de la Commemoratio como en la narración de la vida del santo: una, cuando María se le aparece llevando en sus manos el De uirginitate; otra, cuando le hace entrega de su obsequio ${ }^{41}$.

El texto del cerratense dedicado al santo es, como también ha demostrado Martín Igle$\operatorname{sias}^{42}$, una de las fuentes empleadas por el fraile franciscano Juan Gil de Zamora ${ }^{43}$ para

España medieval en traducción. Ildefonso y Julián de Toledo (BHL 3917 y 4554), Isidoro de Sevilla (BHL 4488) y Froilán de León (BHL 3180)", Veleia, 28 (2011), pp. 232-242.

39 Una aproximación a las obras de Rodrigo de Cerrato y Juan Gil de Zamora desde el punto de vista de la predicación puede verse en Javier Pérez-Embid WAMBA, "Sobre el trasfondo social de la predicación mendicante en Castilla y León (siglo XIII)", Erebea, 1 (2011), pp. 103-136.

40 De que la obra de Bernardo había sido compuesta por expreso pedido del rey, hay sobrada constancia a partir de los prólogos que se conservan de la compilación latina, pero por su fragmentarismo no era posible probar la relación precisa entre ambas obras. Cf. Javier Pérez-EmBid WAMBA, Hagiología y sociedad, p. 257. A partir de los recientes descubrimientos de manuscritos de la versión castellana de la obra de Bernardo, que permiten comparar el texto con la General estoria, Bautista ha demostrado las afinidades entre ellas, lo que le permite avanzar significativamente sobre la hipótesis de que la compilación del briocano fue empleada como fuente de esta última. Este estudioso reformula además la datación propuesta por Díaz y Díaz, que había propuesto el lapso comprendido entre 1257 y 1273, para situar la versión latina entre 1270 y 2175, en función de su uso de la obra de Vincent de Beauvais, y la castellana, hacia el final del reinado de Alfonso X. Francisco Bautista, "Alfonso X, Bernardo de Brihuega y la General estoria", Atalaya, 17 (2017), consultado el 12-01-2020, http://journals.openedition.org/atalaya/2954. Recientemente se han hallado dos fragmentos pertenecientes a la redacción castellana de la obra del briocano en el Arquivo Histórico Provincial de Ourense, a la luz de los cuales Pichel revisa algunas de las propuestas de Bautista relativas a la relación entre las diversas traducciones y sus estadios redaccional. Cf. Ricardo Pichel, "Las Vidas y pasiones de los Apóstoles de Bernardo de Brihuega a la luz de un nuevo testimonio castellano", en Homenaje al Prof. Joaquín Rubio Tovar, Universidad de Alcalá de Henares, Alcalá de Henares, 2021, pp. 55-68.

41 La primera aparición se halla en la Commemoratio, p. 225, 11. 25-30 y en la uita, p.308, 11. 26-39; la segunda se encuentra en la p. 225, 11. 39-45 y en las pp. 308-309, 11. 39-25 de esas mismas secciones. Francisco Villamil Fernández (ed.), Vitas sanctorum.

42 José Carlos Martín Iglesias, Eduardo Otero Pereira, (eds.), Juan Gil de Zamora, Legende sanctorum, Instituto de Estudios Zamoranos "Florián de Ocampo", Zamora, 2014, pp. 38, 162-163.

43 Además de los textos que aquí consideramos, consignada como BHL 3924 se incluía -con reservas- una narración relativa a san Ildefonso atribuida a Juan Gil de Zamora en la primera edición de la Bibliotheca Hagiographica Latina que se eliminó en las sucesivas. La referencia había sido tomada de Tomás Tamayo de Vargas (Acta Sanctorum, Ianuarii, Apud Ioannem Meursium, Amberes, t. 2, 1643, pp. 537-538), quien evidentemente seguía el texto de la Summi Templi Toletani Descriptio de Blas Ortiz (Apud Ioannem Ayala, Toledo, 1549, ff. XxxvII v - XLII r). Blas Ortiz, sin embargo, indica que toda la relación del hallazgo del cuerpo del santo dimana de Juan Gil de Zamora (quę omnia Ioannes Egidius Zamoranus ordinis minorum vir apprime eruditus usque ad sua tempora, quam diligentissime descripsit, f. XLI v), sin que lo cite de manera textual. Quizá sobre la base de la copia de la que Ortiz disponía se haya realizado la que Juan García Loaysa y Mendoza encargó a Jerónimo Torres a finales del siglo XVI. Cf. José Carlos 
la composición de la entrada Aldeffonsus ${ }^{44}$ en sus Legende sanctorum [BHL -], una voluminosa compilación de vidas de santos y otras festividades litúrgicas. La comparación de los textos revela la dependencia de Juan Gil respecto de las Vitae sanctorum, pero también la utilización de otras fuentes como el Elogium beati Ildefonsi de Julián de Toledo [BHL 3917], la que se atribuyó a Eladio o Cixila $[B H L 3919]^{45}$ y la uita anónima ${ }^{46}$. El final del texto, en cambio, en el que se relata al traslado de las reliquias desde la sede episcopal del santo y el hallazgo de su cuerpo en el templo de san Pedro en Zamora ${ }^{47}$, se debería al propio franciscano. Juan Gil remite aquí a la autoridad de don Suero Pérez de Velasco, quien, como garantía de la veracidad de su relato, le ha narrado lo acontecido en persona ${ }^{48}$. García ha explorado este hecho en conexión con los intereses de este obispo zamorano respecto de la sede compostelana, de la que era por entonces sufragánea. Según sugiere, el hecho de que el relato de Juan Gil sea la única fuente de su tiempo referida al hecho no haría más que reforzar la idea de que debió tratarse de una maniobra orquestada por don Suero ${ }^{49}$.

Las reliquias ildefonsinas, así, enlazaban a Zamora con el ilustre pasado visigótico y hacían de ella centro de peregrinación. La inuentio culmina, pues, con una serie de milagros. En esta última sección Juan Gil anuncia una estructuración bipartita:

"Sed primo reuelaciones premitemus, quas Virgo uirginum, almiflua mater Christi, et beatissima uirgo Leocadia sibi modo mirabili ostenderunt, secundario suscribemus alia miracula, que ipsius meritis nostris temporibus contigerunt ${ }^{\prime \prime 50}$.

\footnotetext{
Martín Iglesias, Eduardo Otero Pereira (eds.) Juan Gil de Zamora, Legende sanctorum, pp. 122-123. La cita que Manuel Risco adjudica a Juan Gil debió tomarla de Blas Ortiz o Tomás Tamayo de Vargas. Manuel Risco, España sagrada, Oficina de Blas Román, Madrid, t. 37, 1789, p. 289.

44 Ibidem, pp. 152-169.

45 Cf. Valeriano Yarza Urquiola, "La Vita vel Gesta Sancti Ildefonsi", José Carlos Martín Iglesias (ed.), "Vita s. Ildefonsi (BHL 3919)", La Hispania visigótica y mozárabe. Dos épocas en su literatura, C. Codoñer (coord.), Mª A. Andrés Sanz, S. Iranzo Abellán, J. C. Martín Iglesias y D. Paniagua Aguilar, Universidad de Extremadura, Universidad de Salamanca, Salamanca, 2010, pp. 371-376.

46 José Carlos Martín Iglesias, "Una 'Vita s. Ildefonsi' inédita".

47 Como ha observado ya José Carlos Martín Iglesias, "Una 'Vita s. Ildefonsi' inédita", los textos identificados como BHL 3923 y BHL 3925-3926, editados por el P. Fita a partir del códice matritense de la Historia canonica ac ciuilis del zamorano, coinciden con la uita que hallamos en su legendario. Fidel FitA, "Traslación e invención del cuerpo de San Ildefonso. Reseña histórica por Gil de Zamora", Boletín de la Real Academia de la Historia 6 (1885), pp. 60-71.

48 "[...] sicut etiam prefatus uenerabilis pater dominus Suggerius, episcopus Zamorensis michi retulit oraculo diuine uocis [...]”. José Carlos Martín Iglesias, Eduardo Otero Pereira (eds.) Juan Gil de Zamora, Legende sanctorum, 11. 257-258, p. 161.

49 Charles García, "De Tolède à Zamora, l'errance des reliques de saint Ildephonse au Moyen Âge", Cahiers d'études hispaniques médiévales, 30 (2007), p. 259.

50 José Carlos Martín Iglesias, Eduardo Otero Pereira (eds.) Juan Gil de Zamora, Legende sanctorum, 11. 235-240, p. 162.
} 
Para la primera parte, dedicada a milagros que ocurrieron en vida del santo, se acude una vez más a Rodrigo de Cerrato, mientras que la segunda está compuesta de un grupo de trece milagros contemporáneos, todos ellos de sanación, clasificados como es habitual en la obra del zamorano según su tipología. Así, se suceden curaciones de ciegos, endemoniados, contrahechos y sordomudos, de los que, por regla, se proporciona nombre y lugar de origen.

El tema de las reliquias aparece en varias ocasiones a lo largo de las obras historiográficas de Juan $\mathrm{Gil}^{51}$, donde se menciona, siguiendo a Lucas de Tuy y a Rodrigo Jiménez de $\mathrm{Rada}^{52}$, el traspaso a Asturias de los tesoros de las iglesias de Toledo, entre los que se contaba el arca que contenía libros de Ildefonso y la vestidura obsequiada por la Virgen. A esto agrega también, recogiendo en este punto la opinión generalizada (" $u t$ creditur”), que al mismo tiempo los restos del santo habían sido llevados a la ciudad de Zamora, ausente tanto en el tudense como en el toledano, y que tampoco aparece en otras relaciones sobre el traslado de reliquias de Toledo a Oviedo en las que se recoge el milagro de la Virgen e Ildefonso ${ }^{53}$.

El célebre milagro de la aparición de la Virgen al santo toledano lo incluye también por Juan Gil dos veces en su Liber Marie ${ }^{54}$, que es, al menos en cuanto a su extensión, la principal obra mariana del franciscano ${ }^{55}$. La primera vez se presenta en el quinto tratado,

51 Juan Gil de Zamora, De preconiis ciuitatis Numantine, pp. 192-193. Fidel Fita (ed.), "De preconiis ciuitatis Numantine", Boletín de la Real Academia de la historia, 5 (1884), pp. 131-200. De preconiis Hispanie, Tract. V, cap. 21, pp. 102-103; Ibid., cap. 25, pp. 108-109; Tract. VI, cap. 1, p. 149; Tract. IX, cap. 10, p. 319-320. Manuel de Castro y Castro (ed.), Juan Gil de Zamora. De preconiis Hispanie, Universidad de Madrid, Facultad de Filosofía y Letras, Madrid, 1955.

52 Rodrigo Jiménez de Rada, De rebus Hispanie, IIII. III, p. 118. También se registra, basándose en la uita del Ps. Eladio, el milagro de la Virgen (Ibidem, II. XxXII, p. 73). Citamos por la edición de Juan FernándeZ Valverde (ed.), Roderici Ximenii de Rada Opera omnia, Brepols (Corpus Christianorum Continuatio Mediævalis, LXXII), Turnhout, 1987. El tema de las fuentes historiográficas en la obra de Juan Gil es analizado por María Felisa del Barrio Vega, "Las fuentes clásicas en el De Preconiis Hispanie de Gil de Zamora", Cuadernos de Filología Clásica. Estudios Latinos, 32.1 (2012), pp. 89-120.

53 Entre éstas se cuenta la narración incluida en el ms. Cambrai 804, editada por Kohler, quien considera que fue redactada a finales del siglo XII. Allí se refiere que el arca pasó de Cartago a Toledo, donde fue recibida por san Ildefonso, lo que sirve para introducir el milagro mariano, que es una versión resumida del que se halla en las colecciones universales de milagros marianos. Charles KOHLER (ed.), "Narratio de reliquiis a Hiersolyma Ovetum usque translatis. Sequuntur earumdem miracula", Revue de l'Orient Latin, 5 (1897), pp. 1-21. Cf. Adeline RucQuor, "Un milagro de Santiago en Oviedo (Ms. Cambrai 804)", Compostellanum, LVIII, 3-4 (2003), pp. 393-415. El texto ha sido editado nuevamente por Martín Iglesias incorporando un testimonio hasta ahora desconocido (Paris, Bibliothèque nationale de France, lat. 18123). Cf. José Carlos Martín Iglesias, "La Translatio reliquiarum Ouetum (Díaz 1011): edición y estudio, con noticia de un nuevo manuscrito (Paris, BnF, lat. 18123)", Territorio, Sociedad y Poder, 15 (2020), pp. 87-113.

54 Olga Soledad BohDziewicz (ed.), Una contribución al estudio.

55 Además del Liber Marie, se conserva un oficio, recientemente editado por Pérez Rodríguez, y una sección de sermones marianos dentro de una colección más amplia, que fue objeto de la tesis doctoral de Adrienne Hamy-Dupont, en vías de publicación, a la que ha dedicado numerosos estudios. Estrella Pérez Rodríguez (ed.), Juan Gil de Zamora, Obra poética, Instituto de Estudios Zamoranos "Florián Ocampo", Zamora, 2018. Adrienne Hamy-Dupont, "Juan Gil de Zamora, Apis Dei: hallazgos homiléticos y propuestas", Studia Zamorensia, 13 (2014), pp. 71-93; "Micas collegi et spicas coadunaui, ou comment 
donde observamos cómo utiliza una vez más la compilación de fray Rodrigo. Se trata, en rigor, de una repetición exacta del que encontramos en las Legende sanctorum ${ }^{56}$, repetición que, como se ha señalado en numerosas oportunidades ${ }^{57}$, constituye un rasgo característico del corpus del zamorano, quien reutiliza los materiales compilados en sus distintas obras siempre que le resulta oportuno. Vemos que en el relato de este milagro Juan Gil introduce un añadido al señalar que los testigos del castigo infligido al obispo Siargio tomaron la prenda y la guardaron en el tesoro de la catedral ("in thesauro ecclesie reposuerunt”) y agrega, en concordancia con lo que consigna en sus textos historiográficos: "sed in Asturias tempore persecucionis fuit postmodum reportatur et adhuc creditur ibi esse" ${ }^{58}$.

Lo que resulta llamativo es la localización del relato dentro del plan estructural de esta compilación mariana, ya que este tratado se dedica a la cuestión de la santificación de la Virgen. Dado que el milagro, en esta redacción, cuenta en su comienzo con una clara referencia a la fiesta de la Anunciación y su traslado al 18 de diciembre, habría sido tal vez más esperable hallarlo en el séptimo tratado, que tiene por objeto este momento de la vida de María. En este último, en cambio, hay otras narraciones milagrosas dentro del decimotercer capítulo (De preconiis Annunciationis almiflue Matris Christi), que se entrelazan con pasajes tomados de diversas autoridades mariológicas, al que sigue el capítulo final del tratado, en el que se recogen exclusivamente diez milagros ${ }^{59}$. En este último capítulo aparece una vez más el otro milagro que Juan Gil había insertado en el tratado cuarto, el del hijo del rey de Hungría [Fita 53, Poncelet 1016] ${ }^{60}$.

écrire un sermon marial au XIIIe siècle. Le cas de Juan Gil de Zamora", Memini, 18 (2015), consultado el 18-12-2020, http://journals.openedition.org/memini/740.

56 José Carlos Martín Iglesias, Eduardo Otero Pereira (eds.) Juan Gil de Zamora, Legende sanctorum, pp. 162-163.

57 Cándida Ferrero Hernández (ed.), Liber contra uenena et animalia uenenosa de Juan Gil de Zamora, Reial Acadèmia de Bones Lletres, Barcelona, 2009, pp. 35-36.

58 Una aproximación a las dos versiones contenidas en el Liber Mariae y una tercera, relativa a la inventio de los restos del santo, atribuida tradicionalmenete también al franciscano, puede leerse en Cándida FerRERO HERNÁNDEZ, "La obra latina de Juan Gil de Zamora. Su relación con la literatura contemporánea peninsular", Congreso internacional de latín medieval hispánico, 12-15 de outubro de 2005, Paulo Farmhouse Alberto; Aires Augusto Nascimento (coords), Universidade de Lisboa, Centro de Estudos Clássicos, Lisboa, 2006, pp. 471-480. Sobre el tema véase también José Carlos Martín Iglesias, "Una 'Vita s. Ildefonsi' inédita”, pp. 193-204. En su edición de las Legende sanctorum de Juan Gil de Zamora Martín Iglesias proporciona con detalle las fuentes empleadas para la redacción del apartado sobre la vida del santo. $C f$. José Carlos Martín Iglesias, Eduardo Otero Pereira (eds.) Juan Gil de Zamora, Legende sanctorum, pp. 152-169.

59 En el capítulo decimotercero se hallan Fita 52, Poncelet 508; Fita 50, Poncelet 1012; Fita 53, Poncelet 1016; Fita 41, Poncelet 1011 y en el decimocuarto capítulo, Fita 54, Poncelet 1078; Fita 45, Poncelet 1082; Fita 55, Poncelet 22; Fita 46, Poncelet 1447; Fita 32, Poncelet 1443; Fita 56, Poncelet 412; Fita 57, Poncelet 1295; Fita 17, Poncelet 1597; Fita 58, Poncelet 1368.

${ }^{60}$ Como hemos señalado, el milagro, aparece dos veces con algunas diferencias redaccionales. Este relato cuenta con diversas variantes, como la que aparece en la colección atribuida a Cesario de Heisterbach, que hace del personaje principal no hijo de un rey de Enrique de Hungría, sino un hermano de Carlomagno. Comparte, no obstante, la característica de ser un milagro asociado a la celebración de la Concepción de María, ausente en otra variante muy difundida del milagro, en la que el personaje es un clérigo de la ciudad de Pisa, que también incluye Juan Gil en su compilación [Fita 43, Poncelet 109]. Alfons HiLka, Die Wundergeschichten des Caesarius von Heisterbach, Hanstein, Bonn, vol. 3, 1937, pp. 187-188. 
En esta narración uno de los dos hijos del rey, gravemente enfermo, es curado gracias a la Virgen, motivo por el cual le consagra su castidad. Sin embargo, al morir su hermano, se ve compelido a casarse para ocupar el lugar de aquél. Realizada la ceremonia, recuerda que ese día no había realizado el rezo de las horas de la Virgen y tras expulsar a todos de la iglesia, una vez iniciada la oración, se le aparece la Virgen para recriminarle que ha faltado a su compromiso. Le promete a su vez que, si abandona a su esposa carnal y celebra los sábados en su honor y la fiesta de su concepción, será su esposa celestial. Luego de llevar vida heremítica por siete años, el joven llega a ser patriarca de Aquilea, cumpliendo esta vez la voluntad de la Virgen. La expresión acerca de la festividad es lo suficientemente ambigua como para que, en concordancia con lo que había anticipado Juan Gil en el cuarto tratado, la concepción a la que se alude no sea interpretada necesariamente como la concepción pasiva de María, sino referida a la encarnación de Cristo, lo que permitiría colocar el milagro en el marco del tratado dedicado a la Anunciación. Y aunque ello haría esperable que, por las mismas razones, se incluyera una vez más el milagro del abad Elsino, éste no se halla en el tratado, aunque el zamorano añade otro milagro, que luego reiterará en el tratado decimosexto, sobre un clérigo que se ahoga tras cometer adulterio [Fita 41, Poncelet 1011].

La segunda versión del relato sobre san Ildefonso se encuentra en el decimosexto tratado de la composición mariana de Juan Gil, en el que presenta milagros obrados por la Virgen, clasificándolos a su vez en tratados secundarios según su tipología. Encabezando el quinto de ellos, donde el franciscano reúne diecisiete milagros ${ }^{61}$ que involucran beneficios de María a sus devotos, este texto sobre el santo de Toledo, si bien coincidente en su contenido, difiere del que aparece en el quinto tratado, ya que sigue la versión aquí con la que suelen iniciarse múltiples colecciones universales de milagros de la Virgen originadas en la que se atribuye a Anselmo de Bury (1080-1148) $)^{62}$. Juan Gil reproduce fielmente este texto, aunque omite, sin corregir como lo había hecho en la otra versión del milagro, la información sobre el paradero de la reliquia ildefonsiana, de la que tampoco dan noticia Berceo ni el Rey Sabio.

\section{La Commemoratio Annuntiationis y san Ildefonso de Toledo en los textos alfonsíes}

Como en aquellas colecciones, la de san Ildefonso es la primera narración milagrosa de las Cantigas de Santa Maria, compuesta, en palabras de Disalvo, con el fin de

"reforzar a través de un relato indisolublemente ligado a la materia mariana universal, la importancia de España en la devoción a la Virgen, recordando -al inicio del cancionero- que fue San Ildefonso, 'que primado foi d'Espanna'

\footnotetext{
${ }_{61}$ De acuerdo con la numeración del índice de éstos son: 884, 1341, 1359, 1761, 1604, 413, 861, 1616, 866, 1293 289, 855, 1520, 664, 1229, 627, 267. Cf. Poncelet, op. cit.

62 Cf. Juan Carlos BAYo, "Las colecciones universales de milagros de la Virgen hasta Gonzalo de Berceo", Bulletin of Spanish Studies, 81. 7-8 (2004), pp. 849-871.
} 
(v. 9), quien entonces devolvió a su reino el culto mariano, que los judíos y herejes habían contribuido a menguar (v. 25)"63.

Se trata de una composición breve que a lo largo de sus seis estrofas recoge la alusión al tratado De uirginitate en contra de los judíos, el milagro de santa Leocadia, la aparición de la Virgen para hacer entrega del alba a Ildefonso dando la doble prohibición de que nadie, salvo Ildefonso, pudiera usar la prenda ni sentarse en la silla desde donde ella se le presenta y el castigo infligido a Siargio por su desobediencia.

Al editar por primera vez los milagros de Juan Gil de Zamora, el P. Fita ${ }^{64}$ estableció las correspondencias entre los milagros de la compilación del franciscano y las cantigas. Respecto del de san Ildefonso, observó que la primera versión del zamorano "aventaja" a la del cerratense por incluir el castigo a Sisberto. En realidad, en el zamorense, al combinarse distintas fuentes -el texto de Rodrigo de Cerrato y la uita anónima utilizada por éste mismo en la redacción de su entrada del santo-, se presenta un mismo hecho atribuido a distintos personajes de manera sucesiva. Y ello tiene, a su vez, su origen en la composición realizada por el propio Rodrigo de Cerrato, quien, como hemos dicho anteriormente, en esta parte del relato echaba mano no sólo de la uita anónima, sino también de la narración que aparece en la colecciones de milagros de la Virgen. En éstas el nombre del obispo sucesor de Ildefonso de las distintas versiones como la de Ps. Eladio y la uita anónima, Sisberto, castigado con el destierro por atraverse a usar la misma silla donde se sentó María en su aparición, deviene en Siagrio y la falta que comete, usar la sagrada vestimenta, recibe una pena aún mayor: la muerte.

Mettmann ${ }^{65}$, por su parte, ya que la cantiga se aparta de las colecciones latinas por la inclusión del milagro de santa Leocadia, consideró que su modelo debió haber sido el texto de Rodrigo de Cerrato, hipótesis ya adelantada por Cueto ${ }^{66}$. Coincide también en el nombre del sucesor de Ildefonso, Siargio, con lo que se hace patente su distancia respecto de la versión del Ps. Eladio. En efecto, estos aspectos señalados por Mettmann están presentes en la narración que hallamos en la Vitae sanctorum y, en todo caso, es evidente que la cantiga recoge elementos que hallamos en la formulación narrativa de las colecciones de milagros latinas, pero incorpora además algo ausente en ellas, el episodio de santa Leocadia ${ }^{67}$.

63 Santiago Disalvo, Los monjes de la Virgen: representación y reelaboración de la cultura monacal en las Cantigas de Santa Maria de Alfonso X, Newark, Juan de la Cuesta, Delaware, 2013, p. 103.

${ }^{64}$ Fidel Fita (ed.), "Cincuenta leyendas por Gil de Zamora, combinadas con las Cantigas de Alfonso el Sabio", Boletín de la Real Academia de la Historia, 6 (1885), p. 57.

${ }_{65}$ Walter Mettmann, "Die Quellen der ältesten Fassung der Cantigas de Santa Maria", Text-Etymologie, Untersuchungen zu Textkörper und Textinhalt: Festschrift für Heinrich Lausberg zum 75. Geburtstag, Arnold Arens (ed.), Franz Steiner, Stuttgart, 1987, p. 180.

66 Leopoldo Augusto de CuETo, Estudio histórico crítico y filológico sobre las Cantigas del Rey Don Alfonso el Sabio, Real Academia Española, Madrid, 1897, $2^{\mathrm{a}}$ ed., p. 185.

${ }_{67}$ A pesar de que el milagro de santa Leocadia está en la versión de Gautier de Coinci, Metmann ya ha observado que no constituye en este caso una fuente para la cantiga. Walter MetTmann, "Die Quellen der ältesten Fassung", p. 180. 
Aunque en la segunda cantiga no hay alusiones a la conexión del arzobispo de Toledo con el festejo mariano de diciembre, el epígrafe de la cantiga 413, perteneciente al ciclo de las cinco festas de santa Maria ${ }^{68}$, lo menciona expresamente. El objeto de esta composición es hacer una alabanza de la virginidad de María y no está dedicada a la fiesta de la Concepción ${ }^{69}$, sino a la Conmemoración de la Anunciación. Al menos no es preciso que la imagen del vidrio traspasada por la luz del sol a la que aquí se acude, empleada por Pedro Damián entre otros autores, se use para explicar ese punto doctrinal, asunto de una intensa discusión teológica durante el siglo XIII, sino precisamente el privilegio que san Ildefonso defendió: la virginidad perpetua de la Madre de Cristo. Este mismo milagro contó con una versión en prosa en la Estoria de España, donde puede verse de manera más clara cuáles fueron las fuentes que sirvieron a la urdimbre del relato. Como se indica en los epígrafes de los manuscritos, esta sección se centra en la aparición de María, dando en primer lugar las precisiones cronológicas sobre la asunción al arzobispado de Ildefonso tras la muerte de Eugenio, su formación bajo la vigilancia de san Isidoro y su lucha contra los herejes que se mostraban contrarios al dogma de la virginidad perpetua. El capítulo fundamentalmente se construye, como es habitual, a partir de la Historia de rebus Hispanie de Rodrigo Jiménez de Rada, quien tomó como fuente para su relato la uita anónima. Además de las referencias a su producción literaria y la duración de su pontificado, presentes también en el Elogium de Julián de Toledo, es en el discurso directo de la Virgen donde se advierte de manera más conspicua la relación textual ${ }^{70}$ :

Vita anónima, § 31

\begin{abstract}
"Quoniam mente pura, fide firma in meis laudibus semper permansisti et in laudem meam diffusam in labiis tuis gratiam tam dulci eloquio in corda fidelium depinxisti et lumbos tuos uirginitatis gratia cingulo castitatis precinxisti et uestimentis perpetue glorie iam in hac uita ornetis ut in futuro in celesti illa beatitudine cum seruis Filii mei eterna leticia leteris".
\end{abstract}

Rodrigo Jiménez de Rada, Historia de rebus Hispanie, II. 22

\begin{abstract}
"Quia fide certa, conscientia pura, lumbos tuos uirginitatis cingulo accinxisti, et gracia in labiis tuis diffusa uirginitatis mee gloriam in cordibus fidelium depinxisti, accipe nestem de thesauris Filii mei, ut iam in hac uita uestimento glorice adorneris, et ea in meis et Filii mei sollempnitatibus uestiaris".
\end{abstract}

\footnotetext{
68 El ciclo se inicia en la cantiga 110 y dedica a la Natividad, la Conmemoración de la Anunciación, la Anunciación, la Purificación y la Asunción las número 411, 413, 415, 417 y 419 respectivamente.

69 Esto lo sostiene Walter Mettmann (ed.), Alfonso X, el Sabio, Cantigas de Santa María, Castalia, Madrid, t. 3, 1989, pp. 332-333.

70 El editor remite con un $c f$. en el aparato de fuentes a la vida de Ps. Eladio en virtud de la coincidencia del episodio narrado. Por entonces la uita anónima de san Ildefonso permanecía inédita. Juan FERNÁNDEZ Valverde, (ed.), Roderici Ximenii de Rada Opera omnia, pp. 72-73.
} 
En la Estoria de España, se contrasta además el final de la narración milagrosa con el aporte de las colecciones marianas: "Pero dize en los miraglos de sancta Maria que Siagrio auie nombre, et que se le apreto tanto en el cuerpo aquella vestidura quel mato"71. A diferencia de lo que ocurre en Juan Gil de Zamora, quien a partir de las fuentes empleadas interpreta que hubo dos transgresiones cometidas por personajes diversos ${ }^{72}$, en el texto alfonsí se deja en evidencia que se trata, en rigor, de dos versiones de un mismo hecho, versiones que contraponen sin pronunciarse sobre la veracidad de una $u$ otra. En Rodrigo de Cerrato, al que, según hemos expresado antes, el zamorense sigue en la construcción del relato ildefonsino, veíamos que se combina la uita anónima con el milagro difundido a través de las colecciones.

\section{Consideraciones finales}

En los autores del siglo XIII que aquí hemos considerado en relación a esta narración, la uita atribuida a Eladio y la versión de las colecciones de milagros marianos son fuentes recurrentes, ya sea de manera directa o mediada a través de otra compilación. A la convergencia de fuentes se contrapone en cada caso, cuando éstas son variadas, la diversa interpretación y actitud de los compiladores ante la discrepancia. Inadvertida la identidad del hecho, en Juan Gil la disimilitud de los relatos en los que abreva redunda en dos violaciones sucesivas a la prohibición de la Virgen, primero la de Sisberto, castigado con la muerte y luego la de Siargio, con la muerte. La Estoria de España, por su parte, como decíamos, deja constancia de la discordancia entre las fuentes sobre el nombre y castigo del transgresor, sin un juicio al respecto. En las Vitae sanctorum, en cambio, silenciando la multiplicidad que surge de sus fuentes, sólo se da cuenta de una de esas versiones, la de las colecciones de milagros marianos. Puede decirse que esto se halla en conformidad con la metodología que el cerratense declara en el prólogo de la obra, adaptando críticamente los materiales compilados:

"Sane lectorem non lateat quod in quibusdam sanctorum legendis et aliis eorumdem historiis nonnulli leguntur errores, quedam dicuntur impossibilia, multa ponuntur contraria. At ego diligenti studio errores correxi, impossibilia pretermissi, contraria concordaui" ${ }^{\prime 73}$.

Hemos de finalizar este recorrido con dos observaciones sobre lo que señala Javier Pérez-Embid Wamba en relación con la evolución litúrgica del siglo XIII a partir de la

\footnotetext{
71 Ramón Menéndez Pidal (ed.), Primera crónica general de España, Gredos , Madrid, 1977, t. 2, p. 282 .

72 "In predicta uero sede, ubi Virgo sedit, nullus postea sedem presumpsit nisi Sysibertus episcopus, qui ab ipsa eiectus sede fuit postmodum exilio relegatus. Post ipsum uero Sia $<r>$ gius, archiepiscopus factus, ait [...]”. Juan Gil de Zamora, Liber Marie, tr. V, Olga S. BohDzIEwICZ (ed.), Una contribución al estudio, p. 202.

73 Francisco Villamil Fernández (ed.), Vitas sanctorum, p. 100.
} 
tradición manuscrita de las Vitae sanctorum de Rodrigo de Cerrato. Este autor señala que "la profundización del dogma mariológico explica la eliminación de la consideración de la Purificación de la Virgen, por su resonancia judaica y su sustitución por la fiesta de la Inmaculada Concepción (tras de santa Lucía)" "74. La falta de la fiesta de la Purificación en el lugar previsto en el manuscrito de Segovia, sin embargo, no parece estar ligada a un reemplazo en virtud de una evolución litúrgica y puede justificarse por una omisión en el proceso de copia, lo que motiva que se lo adicione al final del manuscrito y se inserte una nota en el texto, alertando al lector. En todo caso, su ausencia, según creemos, no implica una sustitución por otra fiesta.

Al margen de este caso específico, vemos que en la obra de Rodrigo de Cerrato, como así también la de Juan Gil de Zamora, muchas veces los manuscritos evidencian distintos estadios redaccionales, lo que apunta a un trabajo continuado por parte de los compiladores para perfeccionar sus obras de modo que éstas cumplieran más acabadamente el fin al que estaban destinadas: proveer material adecuado para la predicación. El acceso a nuevas fuentes, entre las que revisten la mayor importancia las compilaciones surgidas en las órdenes mendicantes, como la Legenda aurea, de la que el cerratense toma la mayor parte de los textos que suma en la revisión de su santoral, seguramente propiciaba nuevas redacciones.

Además de obedecer a la disponibilidad de fuentes, la fiesta mariana de diciembre que incorpora Rodrigo de Cerrato en esta redacción de su obra, ligada tradicionalmente al nombre de san Ildefonso de Toledo, sin duda hubo de tener un trasfondo vinculado a la conocida devoción mariana del monarca castellano. Sin embargo, el interés del dominico está puesto más en aclarar y rectificar a quienes atribuyen un motivo errado a esta festividad que en aportar materia predicable para ella, aspecto que no enfatiza tanto su pervivencia local, cuanto la voluntad de dejar sentada la posición de la Orden Dominica respecto de la creciente devoción sobre la Inmaculada Concepción de María, punto doctrinal que seguiría siendo arduamente discutido durante más de cinco siglos.

\section{Bibliografía}

Acta Sanctorum Ordinis sancti Benedicti, Venecia, 1733.

Acta Sanctorum, Ianuarii, Apud Ioannem Meursium, Amberes, t. 2, 1643.

Amos, Thomas L., The Fundo Alcobaça of the Biblioteca Nacional, vol. 1: Manuscripts 1-150, Collegeville (Minnesota), Lisbon, 1988.

Barrio Vega, María Felisa del, "Las fuentes clásicas en el De Preconiis Hispanie de Gil de Zamora", Cuadernos de Filología Clásica. Estudios Latinos, 32.1 (2012), pp. 89-120.

74 Cf. Javier Pérez-Embid Wamba, Hagiología y sociedad, p. 222. El autor se refiere, en rigor, a la fiesta de la Conmemoración de la Anunciación. 
BAssetti, Massimiliano, "Per un'edizione delle "Vitae sanctorum" di Rodrigo del Cerrato”, Hagiographica, 9 (2002), pp. 73-160.

BAutista, Francisco, "Alfonso X, Bernardo de Brihuega y la General estoria", Atalaya, 17 (2017), consultado el 12-01-2020, http://journals.openedition.org/atalaya/2954.

BAYO, Juan Carlos, "Las colecciones universales de milagros de la Virgen hasta Gonzalo de Berceo", Bulletin of Spanish Studies, 81. 7-8 (2004), pp. 849-871.

Biblioteca Nacional de España, Inventario general de manuscritos, Ministerio de Educación Nacional, Dirección General de Archivos y Bibliotecas, Madrid, t. 5, 1959.

Bohdziewicz, Olga Soledad (ed.), Una contribución al estudio de la prosa latina en la Castilla del siglo XIII: edición crítica y estudio del Liber Mariae de Juan Gil de Zamora (tesis doctoral), Facultad de Filosofía y Letras de la Universidad de Buenos Aires, Buenos Aires, 2014.

Bonaventura, Opera omnia, Collegium a S. Bonaventura (ed.), Quarrachi, vol. 3, 1887.

CAnal, José María, "San Ildefonso de Toledo. Historia y leyenda", Ephemerides mariologicae, 17 (1967), pp. 437-462.

Castro y Castro, Manuel de (ed.) Juan Gil de Zamora. De preconiis Hispanie, Universidad de Madrid, Facultad de Filosofía y Letras, Madrid, 1955.

CuEto, Leopoldo Augusto de, Estudio histórico crítico y filológico sobre las Cantigas del Rey Don Alfonso el Sabio, Real Academia Española, Madrid, 1897, $2^{\mathrm{a}}$ ed.

DARY, Marie-Bénédicte "Saint Bernard et l'Immaculée Conception : La question liturgique", Revue Mabillon, 13 (2002), pp. 219-236.

Disalvo, Santiago, Los monjes de la Virgen: representación y reelaboración de la cultura monacal en las Cantigas de Santa María de Alfonso X, Newark, Juan de la Cuesta, Delaware, 2013.

Dondaine, Antoine, “Les editions du 'Vitas Sanctorum' de Róderic de Cerrato", Studia Anselmiana, 63 (1974), pp. 225-253.

Fernández Valverde, Juan (ed.), Roderici Ximenii de Rada, Opera omnia, Brepols (Corpus Christianorum Continuatio Mediævalis, LXXII), Turnhout, 1987.

FÉrotin, Marius, Le Liber Ordinum en usage dan l'église wisigothique et mozarabe d'Espagne du cinquième au onzième siècle, Monumenta Ecclesiae Liturgica, Firmin-Didot, Paris, vol. 5, 1904.

FERrero Hernández, Cándida (ed.), Liber contra uenena et animalia uenenosa de Juan Gil de Zamora, Reial Acadèmia de Bones Lletres, Barcelona, 2009

Ferrero Hernández, Cándida, "La obra latina de Juan Gil de Zamora. Su relación con la literatura contemporánea peninsular", Congreso internacional de latín medieval hispánico, 12-15 de outubro de 2005, Paulo Farmhouse Alberto; Aires Augusto Nascimento (coords), Universidade de Lisboa, Centro de Estudos Clássicos, Lisboa, 2006, pp. 471-480. 
FITA, Fidel (ed.), "Cincuenta leyendas por Gil de Zamora, combinadas con las Cantigas de Alfonso el Sabio”, Boletín de la Real Academia de la Historia, 6 (1885), pp. 54-144.

FitA, Fidel (ed.), "De preconiis ciuitatis Numantine", Boletín de la Real Academia de la historia, 5 (1884), pp. 131-200.

FITA, Fidel, “Traslación e invención del cuerpo de San Ildefonso. Reseña histórica por Gil de Zamora", Boletín de la Real Academia de la Historia 6 (1885), pp. 60-71.

Flórez, Enrique, España sagrada, Imp. Gabriel Ramírez, Madrid, t. 16, 1762.

FríAs, Lesmes, "Antigüedad de la fiesta de la Inmaculada en España”, Miscelánea Comillas, 23 (1955), pp. 27-154.

Fuero juzgo en latín y castellano, Real Academia Española (ed.), Madrid, 1815.

Galbraith, Gretchen R., The Constitution of the Dominican Order, Manchester University Press, Manchester, 1925.

GARCÍA, Charles, "De Tolède à Zamora, l'errance des reliques de saint Ildephonse au Moyen Âge", Cahiers d'études hispaniques médiévales, 30 (2007), pp. 231-259.

Hamy-Dupont, Adrienne "Juan Gil de Zamora, Apis Dei: hallazgos homiléticos y propuestas”, Studia Zamorensia, 13 (2014), pp. 71-93.

Hamy-Dupont, Adrienne, "Micas collegi et spicas coadunaui, ou comment écrire un sermon marial au XIIIe siècle. Le cas de Juan Gil de Zamora”, Memini, 18 (2015), consultado el 18-12-2020, http://journals.openedition.org/memini/740.

Hermann de Tournai, Epistola Hermanni, abbatis S. Martini Tornacensis, de corpore S. Vincentii diaconi Valentiae quiescente et de coenobio ejusdem nomine ibidem consecrato, Analecta Bollandiana, 2 (1883), pp. 243-246.

HiLka, Alfons, Die Wundergeschichten des Caesarius von Heisterbach, Hanstein, Bonn, vol. 3, 1937

IbÁÑez Palomo, Tomás, "La Anunciación del Monasterio de Caleruega (Burgos): contextualización en la Baja Edad Media peninsular", Anales de Historia del Arte, 25 (2015), pp. 19-49.

IHnAT, Kati, “Orígenes y desarrollo de la fiesta litúrgica de la Virgen María en Iberia", Anuario de Estudios Medievales, 49. 2 (2019), pp. 619-643.

JANINI, José, GonzÁlvez, Ramón, Catálogo de los manuscritos litúrgicos de la Catedral de Toledo, Diputación Provincial, Toledo, 1977.

Janini, José, Serrano, José, Manuscritos litúrgicos de la Biblioteca Nacional, Dirección General de Archivos y Bibliotecas, Madrid, 1969.

KoHler, Charles (ed.), "Narratio de reliquiis a Hiersolyma Ovetum usque translatis. Sequuntur earumdem miracula", Revue de l'Orient Latin, 5 (1897), pp. 1-21.

Martín Iglesias, José Carlos (ed.), "Vita s. Ildefonsi (BHL 3919)”, La Hispania visigótica y mozárabe. Dos épocas en su literatura, C. Codoñer (coord.), Mª . A. Andrés Sanz, 
S. Iranzo Abellán, J. C. Martín Iglesias y D. Paniagua Aguilar, Universidad de Extremadura, Universidad de Salamanca, Salamanca, 2010, pp. 371-376.

Martín Iglesias, José Carlos “Una 'Vita s. Ildefonsi' inédita, fuente de Juan Gil de Zamora. Presentación y edición del texto", Estudios de latín medieval hispánico: actas del $V$ Congreso internacional de latín medieval hispánico, Barcelona, 7-10 de septiembre de 2009, José Martínez Gázquez, Óscar de la Cruz Palma, Cándida Ferrero Hernández (eds.), SISMEL, Firenze, 2011, pp. 193-204.

Martín Iglesias, José Carlos, "Ildefonso de Toledo", Diccionario biográfico español, Real Academia de la Historia, Madrid, vol. 27, 2012, pp. 187-188.

MARTín IgLESIAS, José Carlos, "Relatos hagiográficos sobre algunos obispos de la España medieval en traducción. Ildefonso y Julián de Toledo (BHL 3917 y 4554), Isidoro de Sevilla (BHL 4488) y Froilán de León (BHL 3180)”, Veleia, 28 (2011), pp. 209-242.

Martín Iglesias, José Carlos, Otero Pereira, Eduardo (eds.), Juan Gil de Zamora, Legende sanctorum, Instituto de Estudios Zamoranos "Florián de Ocampo", Zamora, 2014.

Martín Iglesias, José Carlos, "La Translatio reliquiarum Ouetum (Díaz 1011): edición y estudio, con noticia de un nuevo manuscrito (Paris, BnF, lat. 18123)", Territorio, Sociedad y Poder, 15 (2020), pp. 87-113.

Martínez Martínez, María José, "Las anunciaciones góticas burgalesas y los ritos hispánico y romano", Codex aquilarensis: Cuadernos de investigación del Monasterio de Santa María la Real, 28 (2012), pp. 203-218.

Menéndez Pidal, Ramón (ed.), 1977, Primera crónica general de España, Madrid: Gredos, t. 1 y 2.

Menéndez Pidal, Ramón (ed.), Primera crónica general de España, Gredos , Madrid, t. $2,1977$.

Mettmann, Walter, (ed.), Alfonso X, el Sabio, Cantigas de Santa María, Castalia, Madrid, t. 1-3, 1986-1989.

Mettmann, Walter, "Die Quellen der ältesten Fassung der Cantigas de Santa Maria", Text-Etymologie, Untersuchungen zu Textkörper und Textinhalt: Festschrift für Heinrich Lausberg zum 75. Geburtstag, Arnold Arens (ed.), Franz Steiner, Stuttgart, 1987, pp. 177-182.

Niemayer, Gerlinde, "Die Miracula S. Mariae Laudunensis des Abtes Hermann von Tournai. Verfasser und Entstehungszeit”, Deutsches Archiv für Erforschung des Mittelalters, 27 (1971), pp. 135-174.

Nieto Gallo, Gratiniano, "Una representación de la Inmaculada en el siglo XV”, Boletín del Seminario de Estudios de Arte y Arqueología, 11 (1944-1945), pp. 109-118.

OrTiz, Blas, Summi Templi Toletani Descriptio, Apud Ioannem Ayala, Toledo, 1549. 
Paniagua, David, "Concilios hispánicos de época visigótica y mozárabe”, La Hispania visigótica y mozárabe. Dos épocas en su literatura, Carmen Codoñer (coord.), Universidad de Salamanca, Universidad de Extremadura, Salamanca, 2010.

Pérez Rodríguez, Estrella (ed.), Juan Gil de Zamora, Obra poética, Instituto de Estudios Zamoranos "Florián Ocampo", Zamora, 2018.

Pérez-Embid Wamba, Javier, Hagiología y sociedad en la España medieval. Castilla y León (siglos XI-XIII), ed.Universidad de Huelva, Huelva, 2002.

PÉRez-EmBid WambA, Javier, "Sobre el trasfondo social de la predicación mendicante en Castilla y León (siglo XIII)", Erebea, 1 (2011), pp. 103-136.

Pichel, Ricardo, "Las Vidas y pasiones de los Apóstoles de Bernardo de Brihuega a la luz de un nuevo testimonio castellano", Homenaje al Prof. Joaquín Rubio Tovar, Universidad de Alcalá de Henares, Alcalá de Henares, 2021, pp. 55-68.

Poncelet, Albert, "Index Miraculorum B.V. Mariae quae saeculis VI-XV latine conscripta sunt”, Analecta Bollandiana, XXI (1902), pp. 241-360.

Risco, Manuel, España sagrada, Oficina de Blas Román, Madrid, t. 37, 1789.

Rucquor, Adeline, "Ildefonse de Tolède et son traité sur la Virginité de Marie", en J.-F. Baudoz et alii, La Virginité de Marie. Communications présentées à la $53 e$ session de la Société française d'études mariales, Issoudun, septembre 1997, París, Médiaspaul, 1998, pp.105-125.

Rucquor, Adeline, "Un milagro de Santiago en Oviedo (Ms. Cambrai 804)”, Compostellanum, LVIII, 3-4 (2003), pp. 393-415.

SAINT-DENIS, Alain, "Édition des sources d'histoire médiévale: Les miracles de sainte Marie de Laon d'Hériman de Tournai', Bulletin du centre d'études médiévales d'Auxerre, 13 (2009), consultado el 18-12-2020, http://journals.openedition.org/cem/11241.

SAINT-Denis, Alain, "Hermannus monachus. Qui était vraiment l'auteur du livre des Miracles de Notre-Dame de Laon ?", Comptes rendus des séances de l'Académie des Inscriptions et Belles-Lettres, 150e année, 3 (2006), pp. 1611-1647.

San Bonaventura, Fortunato de, Commentariorum de Alcobacensi manuscriptorum bibliotheca libri tres, Typographia Academico-Regia, Coimbra, 1827.

SÁnchez Amejeiras, María del Rocío, "Crisis, ¿qué crisis?: sobre la escultura castellana de la primera mitad del siglo XIV", El Trecento en obres. Art de Catalunya $i$ art d'Europa al segle XIV, Rosa Alcoy (ed.), Universitat de Barcelona, Barcelona, 2009, pp. 243-272.

Simonet, Francisco Javier, "Un santoral hispano-mozárabe del siglo X", Ciudad de Dios, V (1871), pp. 105-116 y 192-222.

Twomey, Lesley, The Serpent and the Rose: The Immaculate Conception and Hispanic Poetry in the Late Medieval Period, Brill, Leiden, Boston, 2008.

Villamil Fernández, Francisco (ed.), Rodrigo de Cerrato, Vitas sanctorum. Estudio y edición (tesis doctoral), Universidade de Santiago de Compostela, Santiago de Compostela, 1991. 
Vives, José, FÁBrega, Ángel, "Calendarios hispánicos anteriores al s. XII", Hispania Sacra, 2.3 (1949), pp. 119-146.

VIVEs, José, FÁBrega, Ángel, “Calendarios hispánicos anteriores al s. XIII”, Hispania Sacra, 2.4 (1949), pp. 339-380.

Vives, José, FÁBREga, Ángel, “Calendarios hispánicos anteriores al s. XIII”, Hispania Sacra, 3.5 (1950), pp. 145-161.

Vives, José (ed.), Concilios Visigóticos e Hispano-Romanos, Consejo Superior de Investigaciones Científicas Instituto Enrique Flórez, Barcelona, Madrid, vol. 1, 1963.

WARD, Aengus (ed.), Estoria de Espanna Digital, University of Birmingham, consultado el 13-02-2010, http://estoria.bham.ac.uk/edition/.

Yarza Urquiola, Valeriano "La Vita vel Gesta Sancti Ildefonsi de ps. Eladio: estudio, edición crítica y traducción”, Veleia, 23 (2006), pp. 279-325.

Zeumer, Karl (ed.), Leges visigothorum, MGH, Hahn, Hannover, Leipzig, vol. 1. 1, 1902. 